\title{
UM MOMENTO MUSICAL
}

Maria Helena Nery Garcez

Pertencente a Ritmo Dissoluto, coletânea que Manuel Bandeira publicou em 1924, reunindo composições realizadas no período de 1913 a 1921, está o poema Felicidade (1), pequena obra prima musical. Por informação do autor no seu Itinerário de Pasárgada sabemos que tal poesia é contemporânea ou anterior às de Carnaval, tendo sido criada por volta de 1913, época em que Manuel Bandeira ainda se encontrava ligado à estética tradicional no que diz respeito ao ritmo. Em versos livres serão apenas as composições mais tardias, as últimas de Ritmo Dissoluto.

Atentando para a estrutura externa do poema, observamos que seus versos estão dispostos em três frases musicais: a primeira contendo sete versos e as duas restantes quatro cada uma. Constituindo o fecho do poema aparece um verso isolado. A designação fecho, aliás,

(1). - BANDEIRA, Manuel - Estrela da Vida Inteira. 2a ed., Rio de Janeiro, Livraria José Olympio Editora e Instituto Nacional do Livro, 1970, p. 82:

\section{FELICIDADE}

A doce tarde morre. E tão mansa

Ela esmorece,

Tão lentamente no céu de prece,

Que assim parece, toda repouso,

Como um suspiro de extinto gozo

De uma profunda, longa esperança

Que, enfim cumprida, morre, descansa.

E enquanto a mansa tarde agoniza,

Por entre a névoa fria do mar

Toda a minh'alma foge na brisa:

Tenho vontade de me matar!

Oh, ter vontade de se matar...

Bem sei é cousa que não se diz.

Que mais a vida me pode dar?

Sou tão feliz!

- Vem, noite mansa. 
é imprópria pois tal poema não apresenta uma estrutura fechada, mas, como veremos adiante, o poeta propositadamente não arredonda a estrutura, deixando-a aberta. O metro usado para a maioria dos versos é o eneassílabo, aparecendo apenas três versos tetrassilábicos: o segundo, o décimo quinto e o décimo sexto. Quanto à rima, aparece a interior (nos quatro primeiros versos) e a final. Na primeira estrofe o tipo de rima final predominante é a emparelhada (abbccaa) e nos dois quartetos é cruzada (dede; efef).

A tonicidade não obedece a uma regularidade absoluta. Há, porém, um traço comum: todos os versos apresentam acentuação na quarta e na nona sílaba ,excetuando-se os tetrassílabos que, evidentemente, só apresentam acentuação na quarta. Os versos que apresentam outros acentos além dos nas $4 .^{\mathrm{a}}$ e $8 .^{\mathrm{a}}$ sílabas, são:

$\begin{array}{llllll}1^{\circ} \text { verso } & \text { - Acentos nas: } & 2^{\mathrm{a}} & 4^{\mathrm{a}} & 6^{\mathrm{a}} & 9^{\mathrm{a}} \\ 6^{\mathrm{o}} \text { e } 7^{\mathrm{a}} \text { versos } & \text { - Acentos nas: } & & 4^{\mathrm{a}} & 6^{\mathrm{a}} & 9^{\mathrm{a}} \\ 8^{\mathrm{o}} \text { verso } & \text { - Acentos nas: } & 2^{\mathrm{a}} & 4^{\mathrm{a}} & 6^{\mathrm{a}} & 9^{\mathrm{a}} \\ 9^{\circ} \text { e } 10^{\mathrm{o}} \text { versos } & \text { - Acentos nas: } & & 4^{\mathrm{a}} & 6^{\mathrm{a}} & 9^{\mathrm{a}} \\ 12^{\circ} \text { verso } & - \text { Acentos nas: } & 1^{\mathrm{a}} & 4^{\mathrm{a}} & & 9^{\mathrm{a}} \\ 13^{\mathrm{a}} \text { verso } & - \text { Acentos nas: } & 2^{\mathrm{a}} & 4^{\mathrm{a}} & & 9^{\mathrm{a}} \\ 15^{\circ} \text { verso } & - \text { Acentos nas: } & 2^{\mathrm{a}} & 4^{\mathrm{a}} & & \\ 16^{\circ} \text { verso } & - \text { Acentos nas: } & 1^{\mathrm{a}} & 4^{\mathrm{a}} & & \end{array}$

Há uma certa regularidade na disposição dos acentos secundários e é devido a estas variações uniformes de acentuação que os versos apresentam um ritmo modulado, extraordinariamente musical. A incidência do acento uniformemente sobre a $4 .^{\mathrm{a}}$ sílaba de cada leva-nos a dirigir uma atenção especial para as palavras que a contêm e o levantamento faz-nos concluir que em tal posição estão situadas as palavras fulcrais do poema. Assim, no primeiro verso, é a palavra tarde que se singulariza. E realmente essa a palavra central do verso, pois é a que define todo o ambiente, a atmosfera que vai envolver a poesia. Em torno do acento principal na $4 .^{\mathrm{a}}$ sílaba, há mais dois acentos secundários neste versos e muito importantes para a configuração do ritmo desta poesia, os acentos na $2 .^{\mathrm{a}}$ e na $6 .^{\mathrm{a}}$ sílabas:

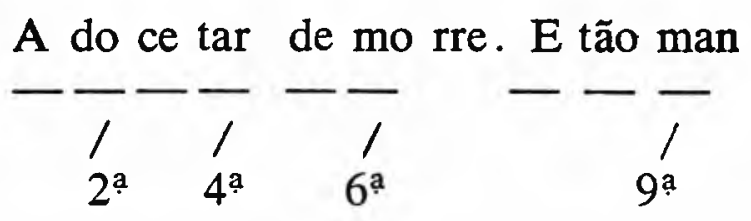

O segundo acento incide sobre a sílaba do de doce, e produz um efeito de alongamento do verso, de maior gravidade, efeito este intensificado ainda mais pelo terceiro acento na $6 .^{\mathrm{a}}$ sílaba. O ritmo torna-se mais pausado e mais musical, transmitindo-nos uma sensação de con- 
tinuidade indefinível, de algo que se vai desdobrando lentamente mas que nunca chega a seu fim. Para essa sensação de continuidade é elemento essencial o significado das palavras aliado às suas sonoridades . $O$ acento incidindo sobre a $1 .^{\mathrm{a}}$ sílaba da palavra morre enfraquece a sílaba seguinte extraordinariamente, e, podemos dizer que ela se torna quase que imperceptível. Porém, esta sonoridade atenuada deixa atrás de si um lastro sonoro que se vai perdendo baixinho mas que não cessa de vibrar nos nossos ouvidos. A ressonância das duas vibrantes - -rre transmite-nos a sensação da ação em decurso, sensação essa principalmente expressa pelo substrato semântico da palavra. O verbo está no presente do indicativo, indicando, pois, ação que se desenrola, e a sonoridade e o ritmo fazem-nos captar a ação desenrolando-se lentamente, indefinidamente. A palavra morre impregna com seu sentido a atmosfera do verso de uma melancolia suave, que se vai desdobrando ao mesmo tempo que a sonoridade do vocábulo. E essa palavra que confere o tom de suave tristeza à atmosfera em que o poema se desenvolve. A sensação de suavidade vem justamente do termo que antecede tarde, termo que confere ternura, doçura ao verso, a palavra doce. Quando o poeta diz a doce tarde morre sentimos imediatamente todo um mundo poético criado em que cada vocábulo atua com um sentido altamente evocador.

Temos, portanto, no primeiro verso uma frase de quatro palavras, das quais três são acentuadas; daí resulta um ritmo lento, pausado, melancólico como a significação da frase. $O$ estudo da sonoridade mostra-nos a existência de uma aliteração de dentais $t$ e $d$, " doce tarde

tão. " À primeira vista poderia parecer-nos estranho e destoante que num poema de atmosfera suave, melancólica, aparecesse uma aliteração com consoantes explosivas; tal estranheza será dissipada quando analisarmos o verso $3 .^{a} \mathrm{com}$ o qual este se relaciona intimamente. O levantamento dos recursos sonoros do poema mostra-nos que a aliteração em dental aparece em todo seu decorrer, que é um recurso sonoro fundamental, juntamente com dois outros tipos de aliteração: a das sibilantes e a dos sons nasais. Veremos como se combinam estes três tipos dentro de um mesmo verso e o efeito que daí se tira. No verso que estamos analisando, o $1 .^{\circ}$, vamos encontrar os dois tipos de associação. Estudaremos o entrelaçamento das aliterações de dentais e sibilantes no $1 .^{\circ}$ e $2 .^{\circ}$ versos, procurando determinar o seu efeito. Temos, portanto, os versos: A doce tarde morre. E tão mansa

\section{Ela esmorece,}

Ao pronunciarmos as oclusivas dentais, pronunciamo-las com mais força do que as sibilantes, e isto faz com que baixemos o tom de voz ao emiti-las, de tal forma que suas terminações tornam-se imper- 
ceptíveis, perdem-se no infinito. E o mesmo caso da sonoridade da palavra morre. Principalmente devido à rima interior: doce e esmorece produz-se em nós uma sensação de continuidade indefinida, de sussurro que paira na atmosfera. Logicamente o que fornece a base para a criação deste efeito é o significado do verbo esmorecer, que encerra algo de impreciso, de fluido, de desintegrador.

A aliteração em nasal: tão mansa seguida de sibilante também produz uma associação feliz, pois a ressonância nasal de tão, que vai se intensificar em mansa casa-se admiravelmente bem como o sibilo prolongado da última sílaba: sa. O enjambement que liga o $1 .^{\circ}$ ao $2 .^{\circ}$ verso é muito bem torneado, pois o ritmo ganha aí uma modulação etérea, que nos lembra os contornos ondulantes e imprecisos dos quadros impressionistas. E uma ampla curva mas ligeiramente delineada esta que o ritmo aí descreve. A escolha de um metro diferente, justamente a metade do metro principal foi muito acertada, pois os dois versos constituem de tal forma uma unidade ao nosso ouvido que o sentimos como um verso único. $\mathrm{Na}$ realidade há só um verso para o ouvido e dois para a vista, e a disposição gráfica é um modo de sugerir o movimento ondulante, de vai e vem. Após esmorece temos uma pausa mais longa que, vai atrair nossa atenção para o verso seguinte, que começa num tom musical mais elevado.

No terceiro verso encontramos o ritmo regular apresentando dois acentos, na $4 .^{\mathrm{a}}$ e $9 .^{\mathrm{a}}$ sílabas. Vemos que o acento principal cai sobre a sílaba - men - da palavra lentamente. O significado desta palavra, intensificado pelo acento, vem reforçar a impressão de movimento pausado, compassado. Combinam-se neste verso as aliterações em dental e em nasal: tão lentamente; da aliança destas sonoridades resulta um efeito muito expressivo e que dá margem a uma interpretação de um traço sonoro do poema, a que aludimos no $1 .^{\circ}$ verso. O poeta especifica neste $3 .^{\circ}$ verso o tipo de céu que contempla: é um céu de prece. É hora do crepúsculo, já o sabemos, pois a "tarde morre", e esta especificação - prece - nos leva a crer que se trate da hora do Angelus e que o poeta se refira a isto ao ouvir os sinos tanger. Ora, é a sonoridade onomatopáica, tanto no $1 .^{\circ}$ verso como no $3 .^{\circ}$, que nos leva a esta interpretação. E também o que explica a presença das consoantes oclusivas num poema de atmosfera suave, tranqüila. São as badaladas de um sino que estão expressas por meio de palavras onomatopáicas, como: tão $\left(10^{\circ}\right.$ verso $)$ seguida de mansa, e tão (3..$^{\circ}$ verso) aliada a este admirável lentamente. Há uma sonoridade de ressonância, de vibração, devido à repetição do ditongo nasal de tão em mansa, o mesmo ocorrendo no verso $3 .^{\circ} \mathrm{com}$ tão lentamente. 
Compreende-se também mais nitidamente o porquê de um ritmo tão pausado, tão compassado, tão musical, pela sua adequação ao compasso das baladas de um sino. Encontramos ainda na análise sonora deste verso a sequiência céu de prece, nova aliteração de sibilantes, enquanto ainda se exerce sobre nosso ouvido o influxo mágico da palavra desintegradora esmorece.

As sibilantes, como vemos pela análise, constituem o substrato da estrutura sonora do poema, fornecendo como que a silenciosa música de fundo, que se ouve mas não se escuta, o ciclo quase impercetível sob o qual ressoam as combinações de aliterações nasais e dentais.

O quarto verso enfileira-se na mesma linha sônica do final do 3. Estamos novamente em face de uma rima interior: parece rimando com a última palavra do $3 .^{\circ}$ verso prece. O ritmo é escorregadio, deslizante, de uma ligeireza flutuante, principalmente devido à sonoridade, ao substrato sibilante. O ritmo dos versos $3 .^{\circ}$ e $4 .^{\circ}$ é ondulatório; no verso $3 .^{\circ}$ há um ponto culminante na $4 .^{\circ}$ sílaba -menapós o que novamente a onda sonora decresce e lentamente se espraia para um final de verso que é infinito, que é um sussurro indeterminado e impreciso, emendando-se noutra sonoridade siblante (assim). Acontece o mesmo no verso $4 .^{\circ}$ : a onda sonora eleva-se até a $4 .^{a}$ sílaba, parece, que é o ponto culminante, e tomba logo em seguida numa sílaba sibilante que é rima interior da palavra prece, aumentando portanto a sensação de musicalidade e de ritmo. Não há uma pausa longa aqui; pelo contrário, ela é quase que imperceptível, continuando a queda da onda sonora até resolver-se na sibilante sonora de repouso. Vemos que as quatro palavras finais dos versos terminam em sibilante, porém, não é somente a sonoridade que nos traz a sensação de continuidade, de música de fundo, mas, simultaneamente, o significado destas palavras. No primeiro verso encontramos mansa - e a palavra diz tudo por si mesma. E evidente que o significado de mansa dá-nos idéia de continuidade, de inércia, de traquiilidade, de estabilização. No $2 .^{\circ}$ verso, temos esmorece, cujo sinônimo, no texto, seria desintegra-se, desfaz-se. A palavra prece sugere-nos paz, serenidade, transcendência, portanto algo também de contínuo, de persistente, de estável. O emprego de palavras imprecisas como: esmorece, parece, não nos transmite imagens claras, nítidas, mas ligeiros vultos, figuras nebulosas, imprecisas. Essa indeterminação, essa névoa da hora do crepúsculo é parte essencial da atmosfera impressionista do poema. A última palavra do $4 .^{\circ}$ verso —repouso - reforça mais a sensação de tranqüilidade, de paz.

A palavra dominante do $5 .^{\circ}$ verso é suspiro; e é para provocar a sensação de uma longa expiração que aparece o enjambement, ligando 
o verso $5 .^{\circ}$ ao $6 .^{\circ}$ No estrato das sonoridades encontramos as aliteraçōes em sibilantes: suspiro de extinto gozo. E aqui a sensação ainda poderá ser de continuidade? Cremos que, apesar da palavra extinto, sentiremos ainda a impressão de continuidade, e isto se explica devido ao termo anterior, suspiro. Se a palavra gozo isolada sugere-nos movimento que dura, vindo, porém, modificada por extinto deveríamos ter a sensação de fim, de parada; ora tal não se dá, porque a influência do termo supiro é mais forte, sendo o dominante do verso. Tal vocábulo neutraliza a ação do particípio, dando-nos novamente a sensação de continuidade, de algo que se desenrola lentamente no tempo, que se prolonga e parece infinda.

Os versos $5 .^{\circ}, 6 .^{\circ}$ e $7 .^{\circ}$ formam uma sequiência rítmica e sonora admiravelmente bem construída. $\mathrm{O}$ verso $5^{\circ}$ obedece ainda ao esquema rítmico binário, ao esquema ondulatório, mas vemos que se o tom sobe e tem seu ponto culminante na $4 .^{a}$ sílaba, em suspiro, ele não desce tão rapidamente como nos outros estudados, mas mantém-se no mesmo timbre, para ir e tombar bruscamente, no início do $6 .^{\circ}$ verso. E essa manutenção do tom dominante, aliada à significação da frase que confere a unidade dos dois versos que torna o enjambement tão deslizante, tão natural, tão suave.

Os ritmos dos versos $6^{\circ}$ e $7^{\circ}$ são iguais. Os acentos dos versos tombam na $4 .^{\mathrm{a}}, 6 .^{\mathrm{a}}$ e $9 .^{\mathrm{a}}$ sílabas, mudando-se, pois, o esquema rítmico em relação aos quatro versos anteriores. Estes tornam-se mais graves, mais compassados, mais lentos. Vemos que o ritmo e a significação adequaram-se perfeitamente nestes versos, pois enquanto as significações nos falam de uma esperança longa, contínua, profunda, que se extingue num suspiro, o esquema rítmico acompanha o sentido, desenvolvendo-se com lentidão, com gravidade, ritmo de cantochão.

No verso $7 .^{\circ}$ o ritmo também corresponde ao sentido, produzindonos o efeito de algo que se alcança com esforço, a duras penas. A palavra fulcral deste verso é "cumprido" que vem precedida do significativo advérbio "enfim", tal associação produz o efeito manifestado acima, de libertação, de alívio.

Quanto aos sons, temos no $6 .^{\circ}$ verso uma predominância de vogais nasais, sendo duas vogais fechadas (profunda, longa) e uma aberta (esperança) $\mathrm{O}$ efeito dêste uma profunda é muito expressivo; há aí o som $u$ desnasalizado, seguido do $u$ nasalizado, o que já o torna mais sonoro e longo, e ainda sob a influência do acento predominante do verso. Ora, o acento alonga a sílaba ainda mais, e por isso o sentido de profundidade, expresso pela palavra "profunda" encontra-se aí muitíssimas vezes intensificado, ecoando nos nossos ouvidos como algo de 
muito interior, que parte do âmago das coisas. Em seguida a profunda aparece o adjetivo longa, quase nas mesmas circunstâncias. Temos uma mudança de timbre de un para on, portanto, uma abertura, e esta sílaba sob o acento tônico é pronunciada mais lentamente que as outras. O sentido da palavra é, pois, intensificado pela acentuação e pela sonoridade.

A segunda estrofe constitui uma quadra, cujas rimas são cruzadas ( $\mathrm{d} \mathrm{e} \mathrm{d} \mathrm{e}$ ) Podemos dividi-la ao meio: nos dois primeiros versos termina-se a pintura do ambiente circundante e a partir do terceiro introduz-se uma personagem, o eu-lírico.

O oitavo verso é acentuado como o primeiro, na $2 .^{\mathrm{a}}, 4 .^{\mathrm{a}}, 6 .^{\mathrm{a}}{ }^{\text {'e }}$ 9. a sílabas, sendo, portanto, um verso pausado, longo. A palavra man$s a$ é a dominante no verso, sobre a qual recai o quarto acento. Impressão de lentidão de paz melancólica, nos é dada pelo verbo agoniza. A estrutura sonora apresenta três tipos de aliterações: 1) nasais: e enquanto a mansa. - efeito de ressonância contínua, principalmente devido ao sentido de enquanto; 2) surge na palavra mansa a sibilante surda aliada à nasal, que vai se ligar à sibilante sonora de agoniza; esta tem a vantagem de vibrar, de ecoar mais, de persistir. .;3) aliteração em $t$ e $d$.

No 90 verso, a palavra importante é névoa e há um acento na $6^{\mathrm{a}}$ sílaba em fria Estratos sonoro e semântico mais uma vez interagindo para precisar melhor a imprecisão da atmosfera, névoa fria: na sonoridade há uma repetição de fricativas conduzindo ao efeito do som que se prolonga. Aqui as fricativas substituem as sibilantes

No $10 .^{\circ}$ verso começa o monólogo lírico. O ritmo é binário, acentuação na $4 .^{\mathrm{a}}$ e $9 .^{\mathrm{a}} \mathrm{s}$ sílabas. A palavra em destaque é minh'alma. O ritmo é descendente depois da $4 .^{\mathrm{a}}$ sílaba. Há no início uma ascenção até o ponto culminante - nhal - e em seguida o declínio ligeiro e gracioso e esta sensação é transmitida por foge, que indica leveza, docilidade. E como se a alma do eu-lírico não opusesse nenhuma resistência à brisa. A impressão que consegue dar é de entrega da alma, de seu ser para a desintegração na brisa, no não-ser.

O $11 .^{\circ}$ verso é dos mais importantes do poema, é a chave para a compreensão do seu ambiente, da atmosfera de tristeza. A paisagem fixada é melancólica, triste, calma mas triste, e o porquê desta tristeza é a disposição anímica do poeta manifestada neste verso. (2)

(2). - Este desejo de matar-se ou de que a morte venha logo é motivo constante na obra de Manuel Bandeira. Em "Vou-me embora prá Pasárgada" encontramos uns versos muito semelhantes a este: 
A tonalidade do verso é decrescente. A $1 .^{\mathrm{a}}$ sílaba é a mais alta e a partir desta, forma-se uma escala que abaixando atinge a nota mais grave de todo o poema. A rima ê aguda, atraindo-nos a atenção para a palavra final, a mais importante deste verso. No estrato sonoro vemos a aliteração em dental: tenho vontade de me matar; tal repetição endurece o verso, confere-lhe um ritmo marcado, que exprime a realidade amarga da vida em contraste com o ambiente etéreo, impreciso, ideal da primeira parte.

Inicia-se a terceira estrofe com um verso de estrutura rítmica ternária, com o primeiro acento na primeira sílaba do verso: - Oh, ter vontade. Há depois da interjeição uma longa pausa e é essa enfase na exclamação e esta pausa que confere a este verso o tom de uma conversa. O verso apresenta um tom de impaciência, de aborrecimento. E o juizo crítico do mundo que o eu-lírico ironicamente repete simulando uma conversa.

No verso $13 .^{\circ}$ segue-se a resposta. A acentuação deste verso cai na segunda, quarta e nona sílabas. Logo após o $2 .^{\circ}$ acento há uma longa pausa que denota impaciência. É um começo de verso forte, com uma oclusiva bilabial seguida de uma pausa longa e de uma ascenção brusca de tom. O ponto mais alto é em cousa, palavra colocada em relevo pelo acento. Em seguida o ritmo tomba, decresce e termina o verso na sibilante sonora $\mathrm{z}$, que nos leva para o domínio dos versos de sonoridade infinita.

O desengano, a frustração e a revolta do eu manifestam-se no verso $14 .^{\circ}$, com a pergunta: Que mais a vida me pode dar? A palavra predominante é vida. A impressão de revolta, de desengano é comunicada pela maneira de interrogar E o tipo de pergunta cuja resposta sabemos de antemão que é negativa. Daí a amarga ironia do: Sou tão feliz! É o desencanto do eu-lírico que se manifesta agora camuflado sob a forma de uma espécie de provocação à vida. Esta lhe nega de repente tudo quanto the prometera, e o poeta, que não quer demonstrar seu sofrimento, afeta uma aparente indiferença, numa ironia amarga, denotadora de revolta. A escolha dos metros curtos para os dois versos finais foi muito acertada. Tornam mais vigorosa e mais concentrada a expressão.

O $16^{\circ}$ verso é o remate final onde o tom é de uma ternura imensa. A invocação da morte assemelha-se ao chamamento de um ente amado, pois ela é desejada como libertação ou também como meio de integração cósmica na atmosfera que o circunda. 
E interessante assinalar a metáfora de morte neste verso derradeiro: noite mansa. Contemplar o lento declínio da tarde invadiu o eu-lírico do desejo de fim, em consonância com a natureza. E assim como a noite é a morte da tarde assim ele aspira a seu próprio fim que seria benfazejo (mansa) Sua vida funde-se de tal forma com o ambiente crepuscular que passam a constituir uma unidade; deste modo a noite - fim da tarde - passa a ser o fim também do eu-lírico, que deseja com suavidade.

A sonoridade nasal deste último verso prolonga-se no esquema sonoro de continuidade e tal efeito é reforçado pelas reticências que sugerem um movimento suave, contínuo, indefinível e uma nostálgica aspiração brotada do mais íntimo.

Poema-crepúsculo, momento musical de uma etérea sutileza é esta peça de Manuel Bandeira, que consegue sugerir o inefável, fixar a atmosfera do ocaso com sua gama rica de imprecisão e de suavidade e traduzir um estado d'alma em perfeita sintonia com o ambiente, um estado d'alma-paisagem . 